\title{
How is a surgeon's experience measured?
}

\author{
Daniele Cristina Cataneo, MD, PhD
}

See related article on pages 998-1004.

Surgeon experience is widely explored to evaluate its influence on perioperative and postoperative outcomes. It is very clear in many areas-like administration, finances, and engineering - that experience is important. But how can we best measure the experience of a surgeon? There is no established method to do it.

Basically, a surgeon's experience in lung cancer treatment, for example, is described in the medical literature by the degree of specialization and the number of surgeries performed per year. Further, the literature suggests a minimal number of procedures assisted by a senior surgeon is required to be qualified to perform a procedure alone.

\section{SURGERY IS ONLY MATHEMATICS AND STATISTICS?}

There are many things in a surgeon's experience that are measurable. For example, where the surgeon's fellowship was completed, the number of surgeries he or she performed during training, and the experience level of the student surgeon's tutor. After fellowship training is complete it is possible to evaluate the number of surgeries performed per year. The help of trained assistants during surgeries and the use of protocols can be very useful, too. But there are many other factors that influence outcomes and none of them are measurable in ways as clear as we, for example, measure comorbidities in patients. There are subjective elements-things like ability and confidence-that I believe liken surgeons to artists.

Surgery is not mathematics; rather, is an art. It can be hazardous at any time, and there are many variables during an operation that cause a surgeon to use judgment and creativity.

\section{IS IT POSSIBLE TO COMPARE SURGEONS?}

There is a meta-analysis published by von Meyenfeldt and colleagues ${ }^{1}$ in which the authors conclude mathematically that a surgeon's specialty and reference hospital are more important than his or her experience, but there is a lack of evidence-based minimum-volume standards. It is very difficult to compare different hospitals with different surgeons trained in different settings and performing different surgeries.

Scheel and colleagues ${ }^{2}$ present an innovative take on this subject. The authors explore postoperative outcomes considering not the surgeon or the hospital surgical volume, but rather the experience acquired over years after cardiothoracic fellowship. They measured the experience of surgeons trained in a single center by the same senior-most surgeon using uniform protocols.

The view of the authors is interesting and they tackle a question I have asked myself: What is more important, a surgeon's maturity, the volume of surgeries performed, or the reference hospital?

Scheel and colleagues have a clear answer: Surgeon experience has no influence on perioperative outcomes, but can affect long-term survival (based on N2 resection).

Finally, all of our questions can be answered. Appropriate training can render a surgeon experienced in performing early-stage lung cancer without complications.

\section{References}

1. von Meyenfeldt EM, Gooiker GA, van Gijn W, Post PN, van de Velde CJ, Tollenaar RA, et al. The relationship between volume or surgeon specialty and outcome in the surgical treatment of lung cancer: a systematic review and metaanalysis. J Thorac Oncol. 2012;7:1170-8.

2. Scheel PJ III, Crabtree TD, Bell JM, Frederiksen C, Broderick SR, Krupnick AS, et al. Does surgeon experience affect outcomes in pathologic stage I lung cancer? J Thorac Cardiovasc Surg. 2015;149:998-1004.

\footnotetext{
From the Thoracic Surgery Division, Botucatu School of Medicine, São Paulo State University, São Paulo, Brazil.

Disclosures: Author has nothing to report with regard to commercial support.

Received for publication Dec 27, 2014; accepted for publication Dec 30, 2014; available ahead of print Feb 4, 2015.

Address for reprints: Daniele Cristina Cataneo, MD, PhD, Thoracic Surgery Division, Botucatu School of Medicine, São Paulo State University, 18618-970 Botucatu, São Paulo, Brazil (E-mail: dcataneo@fmb.unesp.br).

J Thorac Cardiovasc Surg 2015;149:1005

$0022-5223 / \$ 36.00$

Copyright (c) 2015 by The American Association for Thoracic Surgery

http://dx.doi.org/10.1016/j.jtcvs.2014.12.073
} 